\title{
Potential Vorticity Diagnosis of the Key Factors Affecting the Motion of Typhoon Sinlaku (2002)
}

\author{
Chun-Chieh Wu, Treng-Shi Huang, and Kun-Hsuan Chou \\ Department of Atmospheric Sciences, National Taiwan University, Taipei, Taiwan
}

(Manuscript received 14 October 2003, in final form 19 February 2004)

\begin{abstract}
Potential vorticity diagnosis is applied to study the factors contributing to the decrease of the forward motion of Typhoon Sinlaku (2002) and is used to evaluate the reason why the operational Aviation (AVN) model failed to predict this slowdown and had a southward track bias as Sinlaku approached the area offshore northeastern Taiwan. The analysis indicates that the initial deceleration was mainly associated with the retreat of the Pacific subtropical high ( $\mathrm{SH}$ ) under the influence of the deepening midlatitude trough (TR). The upperlevel cold-core low (CCL) played only a minor role in impeding Sinlaku from moving northward, while the continental high $(\mathrm{CH})$ over mainland China strongly steered Sinlaku westward. Because the steering effect from the above four systems ( $\mathrm{SH}, \mathrm{TR}, \mathrm{CCL}$, and $\mathrm{CH}$ ) tend to cancel one another out, the subtle interaction therein makes it difficult to make a precise track forecast. The analyses of the AVN model forecasts show that overestimating the $\mathrm{CH}$ and underestimating the $\mathrm{SH}$ are the main causes for the forecast bias. It is believed that results from this work can provide a useful method to quantitatively determine the key factors affecting the typhoon track. Such an analysis should be able to guide future observing and modeling strategies to improve the forecasts of typhoons.
\end{abstract}

\section{Introduction}

Typhoons over the western North Pacific often move westward or northwestward because of the dominating steering flow associated with the Pacific subtropical high $(\mathrm{SH})$. However, in some cases during the late season as typhoons approach about $130^{\circ} \mathrm{E}$, typhoons may slow down, stall, or even recurve because of the weakening of the $\mathrm{SH}$, as well as the strengthening of the continental high $(\mathrm{CH})$ over mainland China and/or the presence of the deep midlatitude baroclinic wave/trough (TR), thus making the forecast difficult. Sinlaku is a case in point that illustrates this stalling scenario in which some operational forecasting model tracks [e.g., the National Centers for Environment Prediction (NCEP) Aviation (AVN) model tracks as shown in Fig. 1] and a number of forecasts from the operational centers (see Fig. 4) failed to predict its slowdown and mistakenly predicted its southward dip before it approached the area offshore northeastern Taiwan. As a result, an overwarning was issued, that is, all government and business activities in northern Taiwan ceased for one day due to the threat of Sinlaku, whose associated wind and rainfall did not se-

Corresponding author address: Dr. Chun-Chieh Wu, Dept. of Atmospheric Sciences, National Taiwan University, No. 1, Sec. 4, Roosevelt Rd., Taipei 106, Taiwan.

E-mail: cwu@ typhoon.as.ntu.edu.tw riously affect the island of Taiwan (see the satellite images in Fig. 2).

In this paper the potential vorticity (PV) diagnosis (Wu and Emanuel 1995a,b; Shapiro 1996; Wu et al. 2000, 2003) is employed to address the following questions: 1) Why did Sinlaku slow down?; 2) What were the key factors affecting the slowdown?; and 3) Why did the operational numerical models (such as AVN) fail to predict such processes and why did they have a southward bias? By evaluating the relative contribution to the steering flow from the individual dynamical systems, such as the SH over the western North Pacific, the $\mathrm{CH}$ over central China, the upper-layer cold-core low (CCL) to the east of Sinlaku, and the TR over Korea (Fig. 3) from both the analysis fields and model forecasts, and through our recently proposed quantitative analysis (Wu et al. 2003) using the piecewise PV inversion, we can better understand why and how Sinlaku changed its path. Answers to the above questions can also provide useful information to help form new observing and modeling strategies to improve the forecasts of such types of typhoons.

\section{Methodology}

a. Concept of the PV inversion

The use of PV for understanding the evolution of the dynamical system in the atmosphere has been well re- 


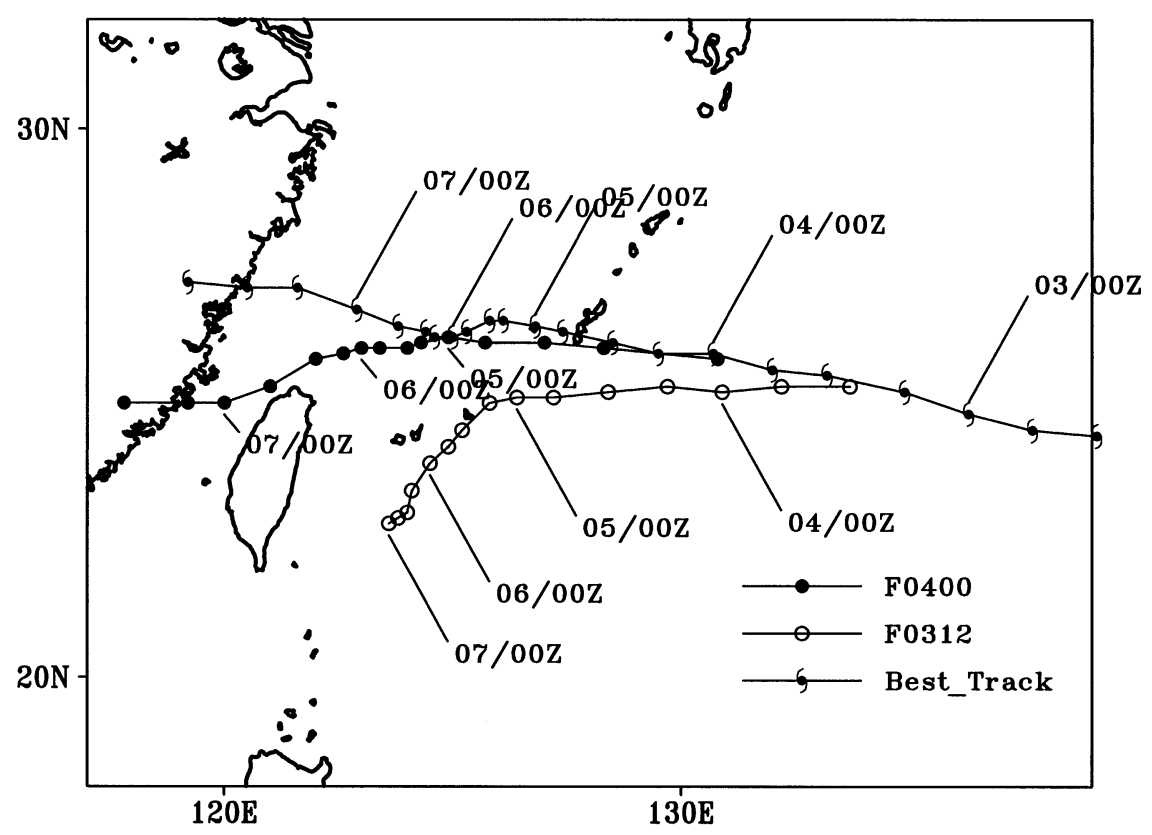

FIG. 1. Best track (from CWB) of Typhoon Sinlaku (2002; indicated by the typhoon symbol for every $6 \mathrm{~h}$ ) from 1200 UTC 2 Sep to 0000 UTC 8 Sep 2002, and the 96-h forecast tracks of AVN starting from 1200 UTC 3 Sep 2002 (indicated by the open circles) and from 0000 UTC 4 Sep 2003 (indicated by the closed circles).

(a) 0000 UTC 03 SEP 2002

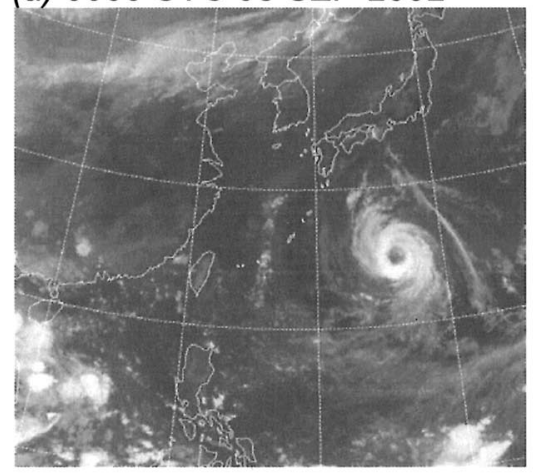

(d) 0000 UTC 06 SEP 2002

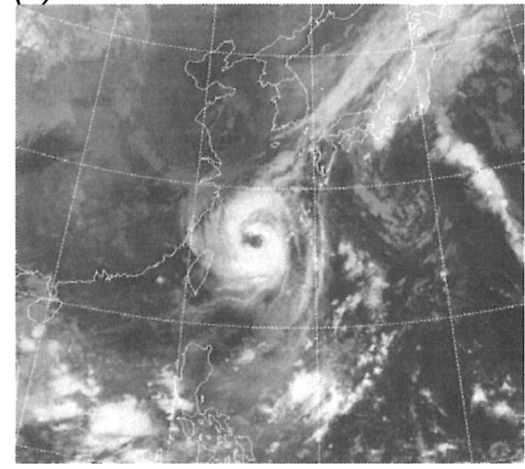

(b) 0000 UTC 04 SEP 2002

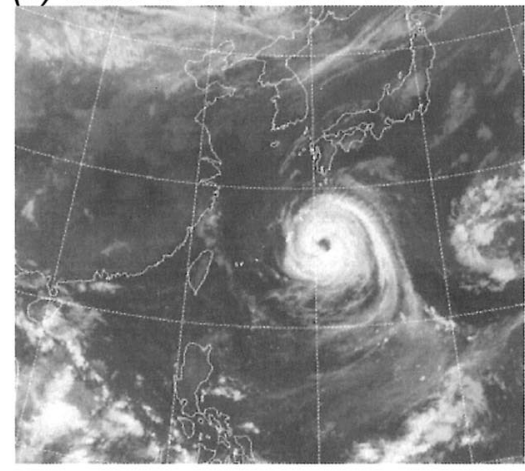

(e) 0000 UTC 07 SEP 2002

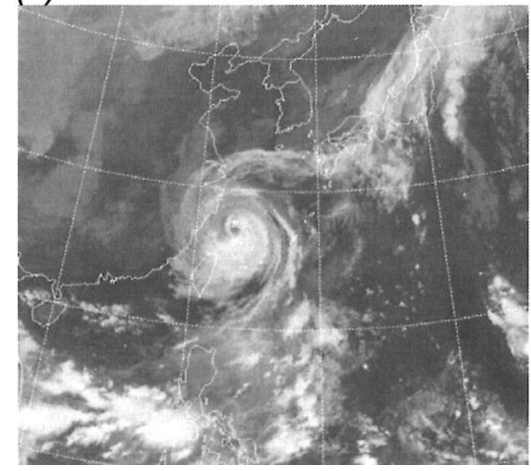

(c) 0000 UTC 05 SEP 2002

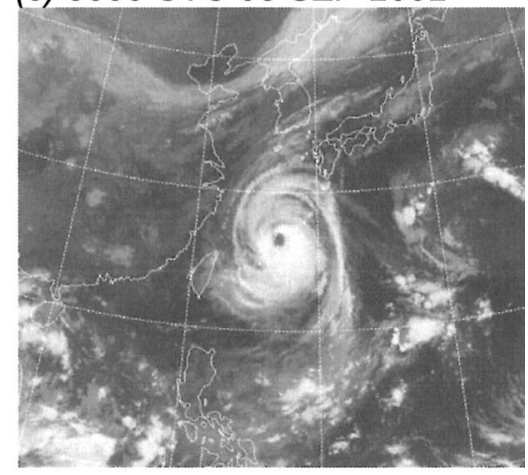

(f) 0000 UTC 08 SEP 2002

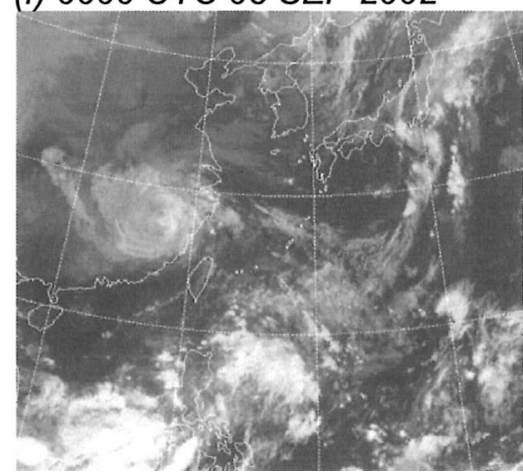

FIG. 2. Japanese Geostationary Meteorological Satellite-5 (GMS-5) IR imageries from 0000 UTC 3 Sep to 0000 UTC 8 Sep 2002. 

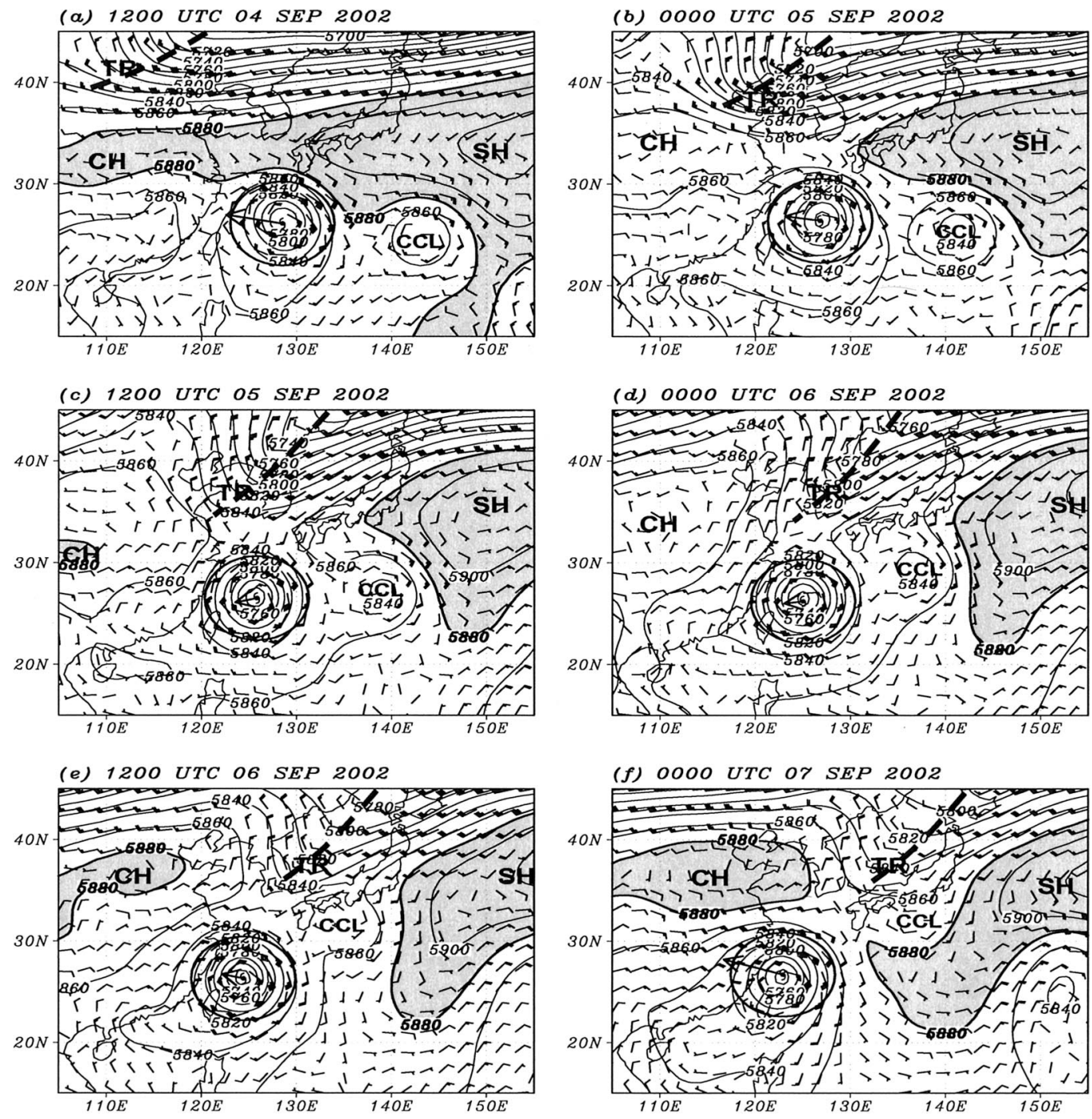

FIG. 3. Geopotential height (contour interval of $20 \mathrm{gpm}$; the area with values larger than $5880 \mathrm{gpm}$ is shaded) and wind at $500 \mathrm{hPa}$ (one full wind barb $=5 \mathrm{~m} \mathrm{~s}^{-1}$ ) starting from (a) 1200 UTC 4 Sep to (f) 0000 UTC 7 Sep. The instantaneous movement of Sinlaku is indicated by the bold arrow, whose length represents the actual translation velocity, and the bold circle shows the scale of $5 \mathrm{~m} \mathrm{~s}^{-1}$.

viewed in Hoskins et al. (1985). Its merit is particularly enhanced with its inversion characteristics. The PV inversion states that given a distribution of PV, a prescribed balanced condition, and boundary conditions, the balanced mass and wind fields can be recovered. Meanwhile, it is shown in Raymond (1992) that the nonlinear balance is a good approximation to flow fields even with a high Rossby number. Using the nonlinear balanced condition (Charney 1955) to invert the Ertel PV, Davis and Emanuel (1991) and Wu and Emanuel (1995a,b) were able to quantitatively examine extratropical cyclogenesis and the steering of tropical cyclones, individually. Formulated on the $\pi\left[\pi=C_{p}\left(p / p_{0}\right)^{\kappa}\right]$ coordinate and spherical coordinates, the two equations to be solved are

$$
\begin{gathered}
q=\frac{g \kappa \pi}{p}\left[\left(f+\nabla^{2} \Psi\right) \frac{\partial^{2} \Phi}{\partial \pi^{2}}-\frac{1}{a^{2} \cos ^{2} \phi} \frac{\partial^{2} \Psi}{\partial \lambda \partial \pi} \frac{\partial^{2} \Phi}{\partial \lambda \partial \pi}\right. \\
\left.-\frac{1}{a^{2}} \frac{\partial^{2} \Psi}{\partial \phi \partial \pi} \frac{\partial^{2} \Phi}{\partial \phi \partial \pi}\right], \quad \text { and } \\
\nabla^{2} \Phi=\nabla \cdot(f \nabla \Psi)+\frac{2}{a^{4} \cos ^{2} \phi} \frac{\partial(\partial \Psi / \partial \lambda, \partial \Psi / \partial \phi)}{\partial(\lambda, \phi)}
\end{gathered}
$$

where $q$ represents PV, $\Phi$ represents geopotential height, $\Psi$ represents streamfunction, $a$ is the earth's radius, $f$ is the Coriolis parameter, $\kappa=R_{d} / C_{p}, \lambda$ is latitude, and $\psi$ is longitude. Given the distribution of $q$, the lateral boundary of $\Phi$ and $\Psi$, and the $\theta$ on the upper and lower boundaries, the distribution of $\Phi$ and $\Psi$ can be solved. Therefore, the nondivergent wind and potential tem- 


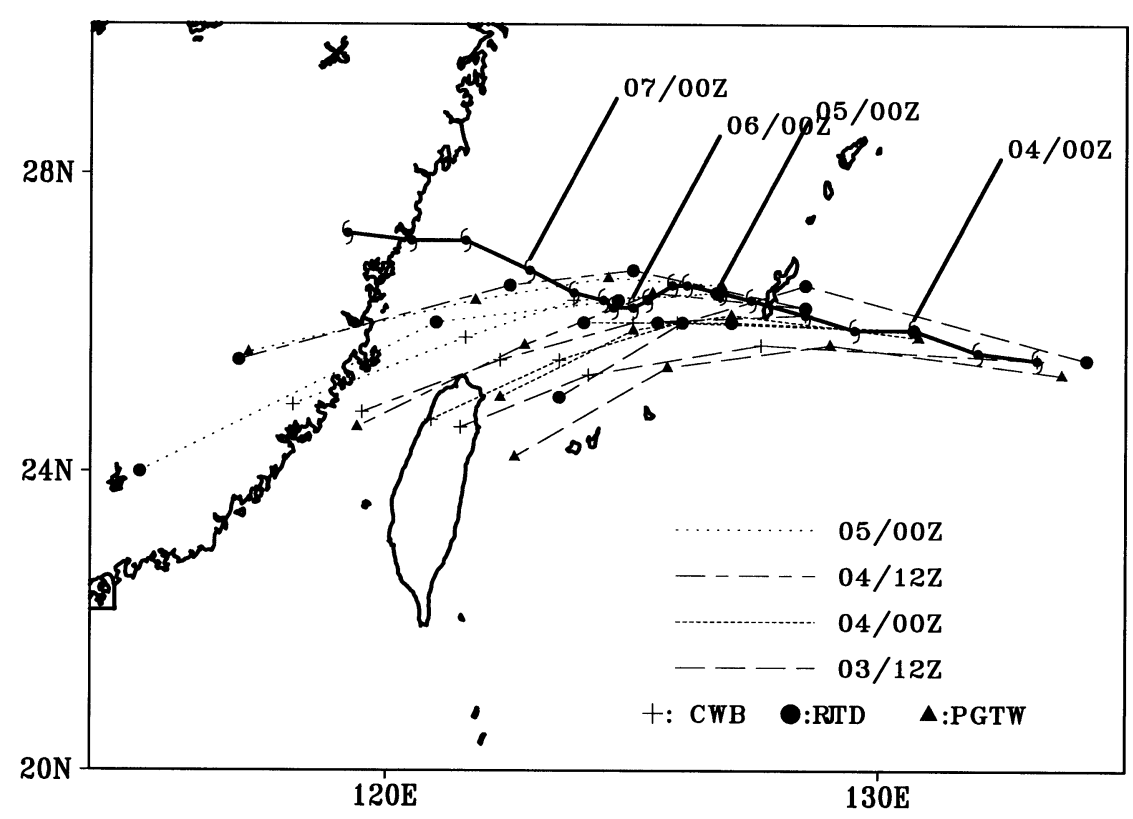

FIG. 4. The best tracks of Sinlaku from 0600 UTC 29 Aug to 0000 UTC 8 Sep and the official forecasts from the CWB, JMA (RJTD), and JTWC (PGTW) from 1200 UTC 3 Sep to 0000 UTC 5 Sep 2002.

perature can also be obtained by the following two relations:

$$
\mathbf{V}=\hat{k} \times \nabla \Psi, \text { and } \quad \theta=-\frac{\partial \phi}{\partial \pi}
$$

Another robust strength associated with the PV inversion is the so-called piecewise PV inversion, that is, when the flow field is appropriately divided into the mean and perturbation components, the above equations can be rederived (Davis 1992) to obtain the balanced fields associated with each individual PV perturbation. Such methods provide a succinct approach to understand how the dynamical systems (PV fields) interact with each other, and how the tropical cyclone track is affected by different PV features in the observational data $(\mathrm{Wu}$ and Emanuel 1995a,b; Shapiro 1996, 1999; Wu et al. 2003) and in the modeled atmosphere (Wu and Kurihara 1996).

\section{b. The PV decomposition}

Shapiro (1996) devised decomposition by taking the axisymmetric vortex as the mean field and the rest as the perturbation and successfully showed that such decomposition can clearly demonstrate how the environmental perturbation interacts with the tropical cyclone vortex.

In this research, to understand how Sinlaku was steered by the perturbation flow fields (such as those associated with the $\mathrm{SH}, \mathrm{TR}, \mathrm{CCL}$, and $\mathrm{CH}$ ), we take the axisymmetric average relative to the center of Sinlaku as the mean part and then follow the approach by
Shapiro (1996) and $\mathrm{Wu}$ et al. (2003) to perform the piecewise PV inversion. In other words, we first construct the azimuthal average of the wind field to obtain the average streamfunction $\bar{\Psi}$, so that the associated average geopotential height can be derived from the nonlinear balanced equation,

$$
\nabla^{2} \hat{\Phi}=\nabla \cdot\left(f_{0} \nabla \bar{\Psi}\right)+\frac{2}{a^{4} \cos ^{2} \phi} \frac{\partial(\partial \bar{\Psi} / \partial \lambda, \partial \bar{\Psi} / \partial \phi)}{\partial(\lambda, \phi)} .
$$

The averaged PV field is then calculated by the following relation:

$$
\begin{gathered}
\hat{q}=\frac{g k \pi}{p}\left[\left(f+\nabla^{2} \bar{\Psi}\right) \frac{\partial^{2} \hat{\Phi}}{\partial \pi^{2}}-\frac{1}{a^{2} \cos ^{2} \phi} \frac{\partial^{2} \bar{\Psi}}{\partial \lambda \partial \pi} \frac{\partial^{2} \hat{\Phi}}{\partial \lambda \partial \pi}\right. \\
\left.-\frac{1}{a^{2}} \frac{\partial^{2} \bar{\Psi}}{\partial \phi \partial \pi} \frac{\partial^{2} \hat{\Phi}}{\partial \phi \partial \pi}\right] .
\end{gathered}
$$

By taking the perturbation field as $\psi^{\prime}=\psi-\bar{\psi}, \phi^{\prime}=$ $\phi-\hat{\phi}$, and $q^{\prime}=q-\hat{q}$, the piecewise PV inversion can be performed to calculate the balanced flow and mass fields associated with each PV perturbation.

In this study, to show how the flow field attributed to different dynamical systems affected the motion of Sinlaku, the whole PV perturbation $\left(q^{\prime}\right)$ is divided into several parts, for example, $q_{\mathrm{SH}}^{\prime}, q_{\mathrm{CH}}^{\prime}, q_{\mathrm{TR}}^{\prime}$, and $q_{\mathrm{CCL}}^{\prime}$, which represents the PV perturbation associated with $\mathrm{SH}, \mathrm{CH}$, $\mathrm{TR}$, and CCL, individually (see relative locations in Figs. 3 and 5). Meanwhile, $q_{\mathrm{OT}}^{\prime}$ indicates the whole PV perturbation other than the above four perturbations. Note that by definition, $q^{\prime}=q_{\mathrm{SH}}^{\prime}+q_{\mathrm{CH}}^{\prime}+q_{\mathrm{TR}}^{\prime}+q_{\mathrm{CCL}}^{\prime}$ $+q_{\mathrm{OT}}^{\prime}$. 

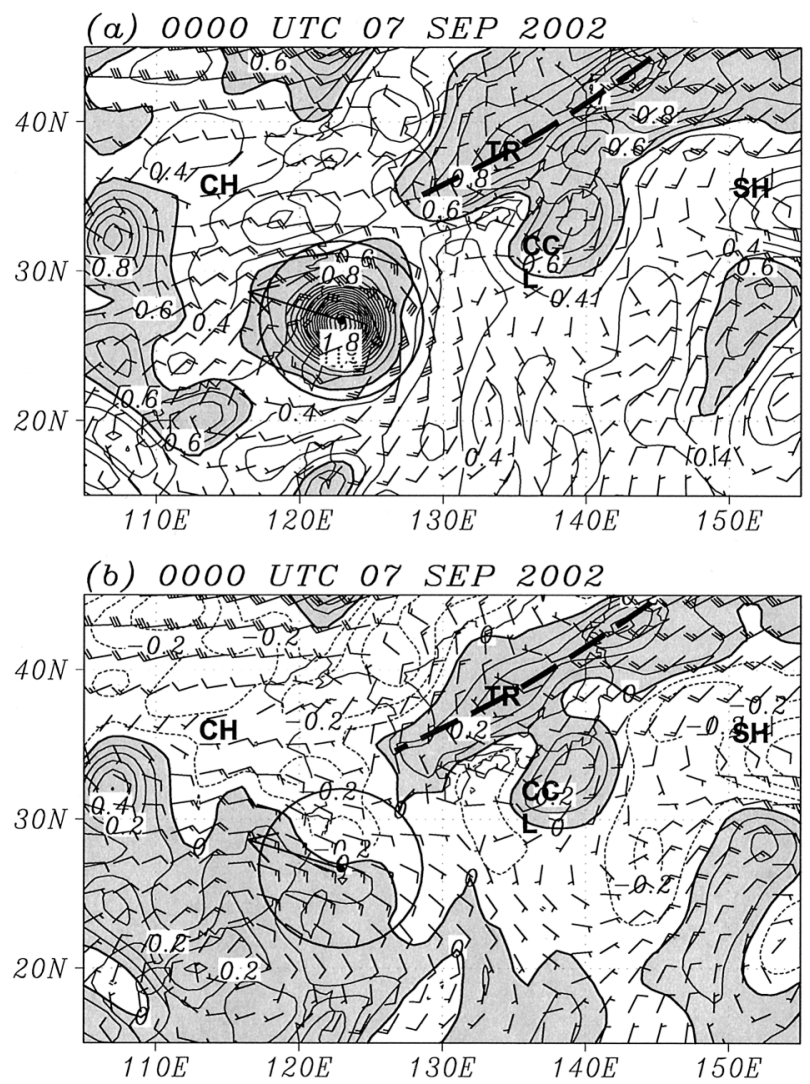

FIG. 5. (a) Potential vorticity (contour interval of 0.1 PVU; PV larger than 0.5 PVU is shaded) and the 975-300-hPa deep-layer-mean wind (one full wind barb $=5 \mathrm{~m} \mathrm{~s}^{-1}$ ); (b) Potential vorticity perturbation (contour interval of $0.1 \mathrm{PVU}$; the area with positive PV value is shaded); and the 975-300-hPa deep-layer-mean perturbation wind (one full wind barb $=5 \mathrm{~m} \mathrm{~s}^{-1}$ ) at 0000 UTC 7 Sep 2002. The definitions of the bold arrow and the circle are as in Fig. 3.

\section{c. Data}

The NCEP AVN global analysis (denoted as AVNA) and forecasts initialized at 1200 UTC 3 September (denoted as F0312) and 0000 UTC 4 September 2002 (denoted as F0400) are used for the above PV diagnosis. The AVN analysis has a resolution of $1^{\circ} \times 1^{\circ}, 181$ (meridional direction) $\times 360$ (zonal direction) grids, and 26 vertical pressure levels. Note that no other operational forecast model outputs are available to us to conduct the same analysis. Nevertheless, we believe that the data from AVN analyses and forecasts (Aberson 2003) are fairly reliable and suitable for this study.

\section{Results \\ a. Synopsis}

Typhoon Sinlaku (2002) formed over the northwestern Pacific on 29 August 2002 (Fig. 1), moved northnorthwestward over the next 2 days, and then moved due west-northwestward following the steering flow associated with the Pacific subtropical high. By 0000 UTC
31 August, it had intensified into a moderate-strength typhoon, moving west-northwestward at a speed of $7 \mathrm{~m} \mathrm{~s}^{-1}$ along the southern edge of the Pacific SH and remaining at the same course for the next 4 days. After Sinlaku passed through the longitude of $130^{\circ} \mathrm{E}$ on 1200 UTC 4 September, its translation speed started to slow down, decelerating from 5.5 to $3.5 \mathrm{~m} \mathrm{~s}^{-1}$ on 0000 UTC 5 September. The speed further decreased to $2 \mathrm{~m} \mathrm{~s}^{-1}$ on 1200 UTC 5 and 6 September, during which time Sinlaku exhibited a west-southwestward and then westnorthwestward track. It accelerated after 1800 UTC 6 September, making landfall at Zhejiang of mainland China on 1200 UTC 7 September, and finally weakened into a tropical depression.

Typhoon Sinlaku was initially steered by the Pacific $\mathrm{SH}$; during its decelerating period between 1200 UTC 4 September and 1200 UTC 5 September, the coverage of the 5880-m geopotential height contours at $500 \mathrm{hPa}$ retreated from central China to east of $130^{\circ} \mathrm{E}$ (Figs. 3a,b). On 1200 UTC 5 September (Fig. 3c) Sinlaku was located at $26.5^{\circ} \mathrm{N}, 125.8^{\circ} \mathrm{E}$, with an upper-level CCL present near $27^{\circ} \mathrm{N}, 139^{\circ} \mathrm{E}$, the $\mathrm{SH}$ to the east of the CCL, a midlatitude TR over Korea, and a $\mathrm{CH}$ over central China (Fig. 3c).

The steering flow became quite weak from 0000 to 1200 UTC 6 September because of the complicated configuration of the flow patterns associated with the weakening $\mathrm{SH}$, evolving $\mathrm{CCL}$, strengthening $\mathrm{CH}$, and passing TR (Figs. 3d,e), thus making it difficult to accurately estimate the steering flow, not to mention the storm motion prediction.

Indeed, from 1200 UTC 3 September to 0000 UTC 4 September, as shown in Fig. 4, all official forecasts from the Central Weather Bureau of Taiwan (CWB), Japan Meteorological Agency (JMA/RJTD), and Joint Typhoon Warning Center (JTWC/PGTW) predicted that Sinlaku would turn southward to affect the Taiwan area when it approached $125^{\circ} \mathrm{E}$, that is, consistent with the southward bias of a number of operational forecast models (G. Lu, Central Weather Bureau, Taiwan, 2002, personal communication). In other words, most forecasts at 1200 UTC 3 September predicted that Sinlaku would make landfall at northeastern Taiwan within $72 \mathrm{~h}$ or later (i.e., 1200 UTC 6 September). However, Sinlaku did not make landfall at Taiwan as predicted. It moved slightly southward for only about $0.4^{\circ}$ between 1200 UTC 5 September and 0000 UTC 6 September before heading west-northwestward to southern mainland China. In all, the subtle inaccuracy in track prediction resulted in a huge error in wind and rainfall prediction in northern Taiwan, and the overwarning of the storm caused great consternation in Taiwan.

\section{b. PV diagnosis}

To highlight the PV features associated with Sinlaku, $\mathrm{SH}, \mathrm{CH}$, TR, and CCL, an example time (0000 UTC 7 September) is chosen to show the PV field ( $q$; Fig. 5a), 


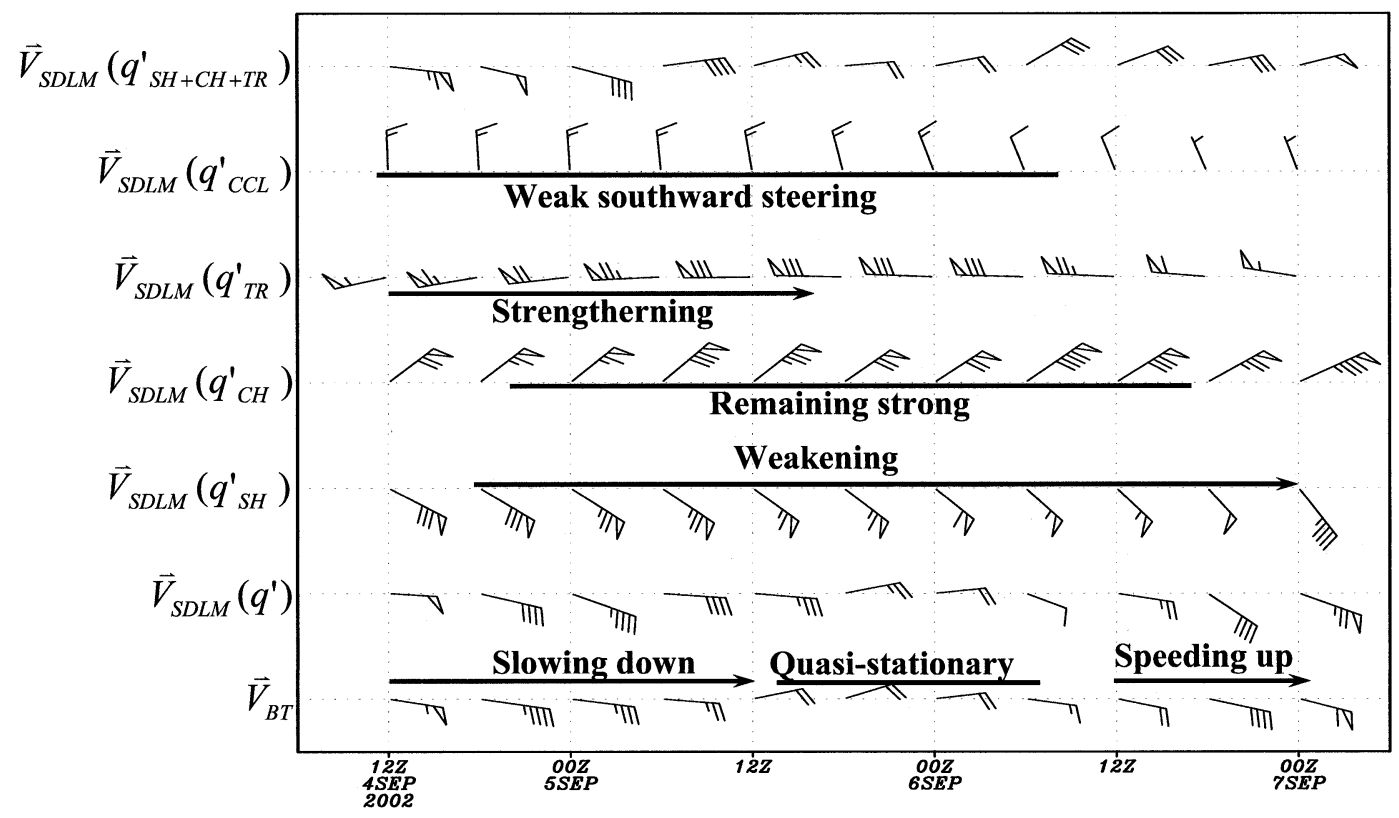

FIG. 6. The time series of the movement of Sinlaku $\left(\mathbf{V}_{\text {Вт }}\right)$ and the steering flow (averaged in the inner $3^{\circ}$ latitude between 975 and $300 \mathrm{hPa}$ ) associated with the total PV perturbation $\left[\mathbf{V}_{\text {SDLM }}\left(q^{\prime}\right)\right]$, and the PV perturbations of SH $\left[\mathbf{V}_{\mathrm{SDLM}}\left(q_{\mathrm{SH}}^{\prime}\right)\right], \mathrm{CH}\left[\mathbf{V}_{\mathrm{SDLM}}\left(q_{\mathrm{CH}}^{\prime}\right)\right], \operatorname{TR}\left[\mathbf{V}_{\mathrm{SDLM}}\left(q_{\mathrm{TR}}^{\prime}\right)\right]$, and $\operatorname{CCL}\left[\mathbf{V}_{\mathrm{SDLM}}\left(q_{\mathrm{CCL}}^{\prime}\right)\right]$, individually. One full wind barb (a flag) represents $1(5) \mathrm{m} \mathrm{s}^{-1}$.

as well as the PV perturbation $\left(q^{\prime}\right.$; Fig. 5b) and the steering flow $\left(\mathbf{V}_{\text {SDLM }}\right)$, defined as the deep-layer-mean (975-300 $\mathrm{hPa}$ ) wind vector (in bold arrow) averaged over the inner $3^{\circ}$ latitude around each storm center (see Wu et al. 2003).

At 0000 UTC 7 September (Fig. 5a), Sinlaku is located in a region of high $\mathrm{PV}$, with maximum $\mathrm{PV}$ of about 1.8 PVU (1 PVU $=10^{-6} \mathrm{~m}^{2} \mathrm{~s}^{-1} \mathrm{~K} \mathrm{~kg}^{-1}$ ), while the $\mathrm{SH}, \mathrm{CH}, \mathrm{TR}$, and CCL all have their clear individual PV features, very much consistent with the height field in Fig. 3f. Based on the partition indicated in section 2 , the PV perturbation $\left(q^{\prime}\right)$ and 975-300-hPa deep-layermean perturbation wind fields are shown in Fig. 5b. In Fig. 5b, the mean PV associated with Sinlaku has been removed. Therefore, there is no PV signal from Sinlaku. Figure $5 \mathrm{~b}$ shows the PV perturbations associated with the $\mathrm{SH}, \mathrm{CH}, \mathrm{TR}$, and CCL that are used for piecewise $\mathrm{PV}$ inversion.

\section{1) AVN ANALYSIS}

Following Wu et al. (2003), to evaluate the steering flow due to various PV perturbations, the time series of the deep-layer-mean steering flows (Fig. 6) associated with the total $\left[\mathbf{V}_{\text {SDLM }}\left(q^{\prime}\right)\right]$ and each PV perturbation $\left[\mathbf{V}_{\text {SDLM }}\left(q_{\mathrm{SH}}^{\prime}\right), \mathbf{V}_{\text {SDLM }}\left(q_{\mathrm{CH}}^{\prime}\right), \mathbf{V}_{\text {SDLM }}\left(q_{\mathrm{TR}}^{\prime}\right), \mathbf{V}_{\text {SDLM }}\left(q_{\mathrm{CCL}}^{\prime}\right)\right.$, and $\left.\mathbf{V}_{\mathrm{SDLM}}\left(q_{\mathrm{OT}}^{\prime}\right)\right]$ are compared with the actual movement of Sinlaku [estimated from the 12-h best-track positions, i.e., $\left.\mathbf{V}_{\mathrm{BT}}=\left(\mathbf{X}_{t+6 h}-\mathbf{X}_{t-6 h}\right) / 12 h\right]$. Note that by design of the piecewise PV inversion, the summation of the balanced flows associated with $q_{\mathrm{SH}}^{\prime}, q_{\mathrm{CH}}^{\prime}, q_{\mathrm{TR}}^{\prime}, q_{\mathrm{CCL}}^{\prime}$, and
$q_{\mathrm{O}}^{\prime}$ is identical to the balanced flow associated with $q^{\prime}$, that is,

$$
\begin{aligned}
\mathbf{V}_{\mathrm{SDLM}}\left(q^{\prime}\right)= & \mathbf{V}_{\mathrm{SDLM}}\left(q_{\mathrm{SH}}^{\prime}\right)+\mathbf{V}_{\mathrm{SDLM}}\left(q_{\mathrm{CH}}^{\prime}\right)+\mathbf{V}_{\mathrm{SDLM}}\left(q_{\mathrm{TR}}^{\prime}\right) \\
& +\mathbf{V}_{\mathrm{SDLM}}\left(q_{\mathrm{CCL}}^{\prime}\right)+\mathbf{V}_{\mathrm{SDLM}}\left(q_{\mathrm{OT}}^{\prime}\right) .
\end{aligned}
$$

The comparison of the balanced flow associated with each PV perturbation thus provides clear evidence of how the motion of Sinlaku is affected by the presence of $\mathrm{SH}, \mathrm{CH}$, TR, and CCL.

The comparison of the wind barbs in the lower two rows in Fig. 6 shows that the balanced flow associated with the total PV perturbation $\left[\mathbf{V}_{\text {SDLM }}\left(q^{\prime}\right)\right]$ is in general agreement with the motion of the best track $\left(\mathbf{V}_{\mathrm{BT}}\right)$ during the course of this study. The error is always less than about $1 \mathrm{~m} \mathrm{~s}^{-1}$, indicating that the motion of Sinlaku is well represented by the deep-layer-mean steering wind field in the AVN analysis based on the PV-inversion method, and therefore it is valid to use the piecewise PV inversion to diagnose the impact on the steering flow from each individual PV perturbation.

To highlight the issues on the factors affecting the decrease in translation speed of Sinlaku, only the time period between 1200 UTC 4 September and 0000 UTC 7 September is investigated here. Particular emphasis is also put on the relative roles the $\mathrm{SH}, \mathrm{CCL}, \mathrm{CH}$, and TR play in the steering of Sinlaku based on the piecewise $\mathrm{PV}$ inversion.

It is found in Fig. 6 that the presence of CCL brings about a persistently weak $\left(<1.5 \mathrm{~m} \mathrm{~s}^{-1}\right)$ southward advection $\left[\mathbf{V}_{\text {SDLM }}\left(q_{\mathrm{CCL}}^{\prime}\right)\right]$ of Sinlaku from 1200 UTC 4 Sep- 


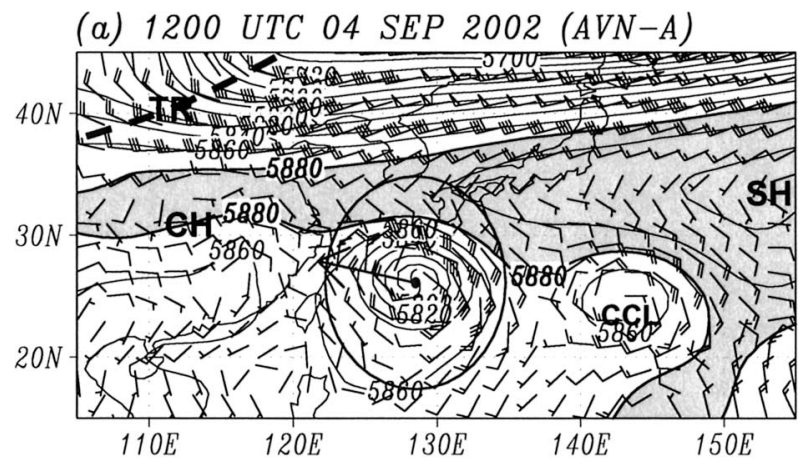

(b) 1200 UTC 04 SEP $2002(F 0312+24 h)$

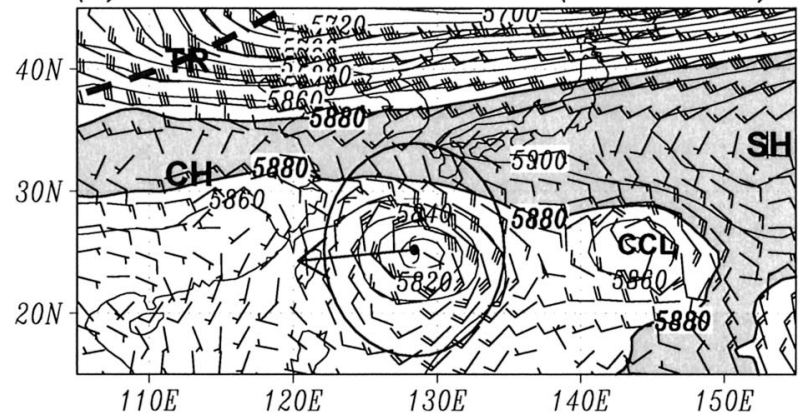

(c) 1200 UTC 04 SEP $2002(F 0400+12 h)$

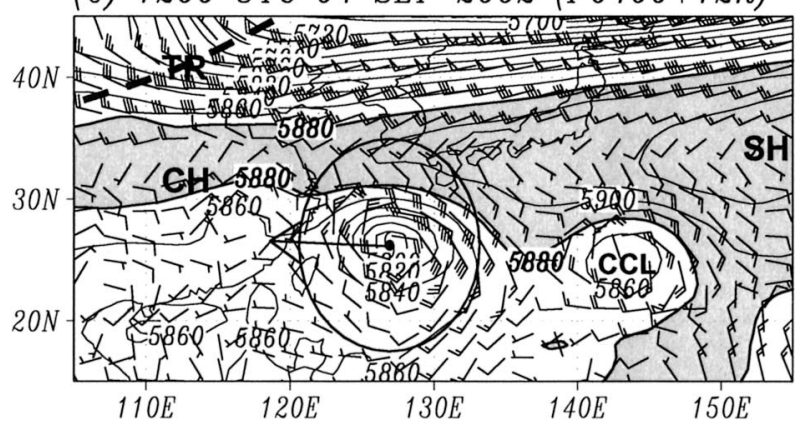

Fig. 7. Geopotential height (contour interval of $20 \mathrm{gpm}$; the area larger than $5880 \mathrm{gpm}$ is shaded) and wind at $500 \mathrm{hPa}$ (one full wind barb $=5 \mathrm{~m} \mathrm{~s}^{-1}$ ) of (a) AVN-A at 1200 UTC 4 Sep 2002, (b) 24-h AVN forecast starting from 1200 UTC 3 Sep 2002 (F0312+24h), and (c) 12-h AVN forecast starting from 0000 UTC 4 Sep 2002 $(\mathrm{F} 0400+12 \mathrm{~h})$. The definitions of the bold arrow and the circle are as in Fig. 3.

tember to 0000 UTC 6 September. As the CCL moves farther east by the TR after 0600 UTC 6 September, it is farther away from Sinlaku and has a minor southward steering effect upon Sinlaku. This result may also help explain why Sinlaku moves slightly toward the north after 1200 UTC 6 September (Fig. 1).

During the time period from 4 to 6 September, the translation speed of Sinlaku keeps decreasing, which is consistent with the reduction of the northwestward steering flow $\left[\mathbf{V}_{\text {SDLM }}\left(q_{\mathrm{SH}}^{\prime}\right)\right]$ associated with the weakening $\mathrm{SH}$ (cf. Fig. 3), that is, from $8 \mathrm{~m} \mathrm{~s}^{-1}$ at 1200 UTC 4 September to $5 \mathrm{~m} \mathrm{~s}^{-1}$ at 1800 UTC 6 September (Fig. 6). Meanwhile, as the SH retreats (Fig. 3), the separation (a) 1200 UTC 05 SEP $2002(A V N-A)$

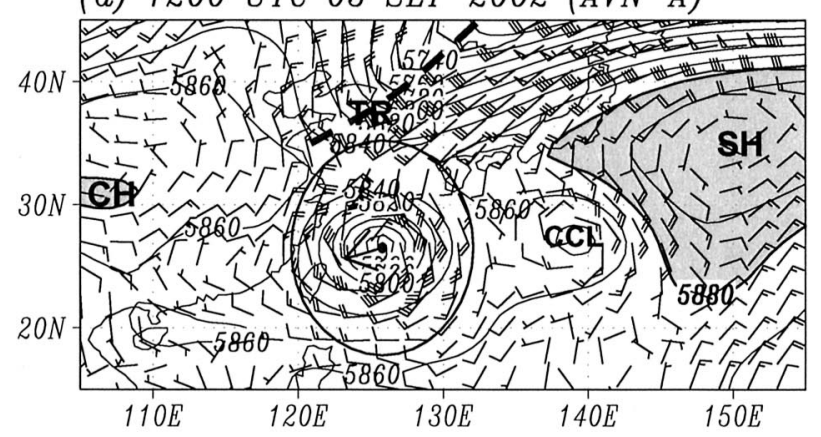

(b) 1200 UTC 05 SEP $2002(F 0312+48 h)$

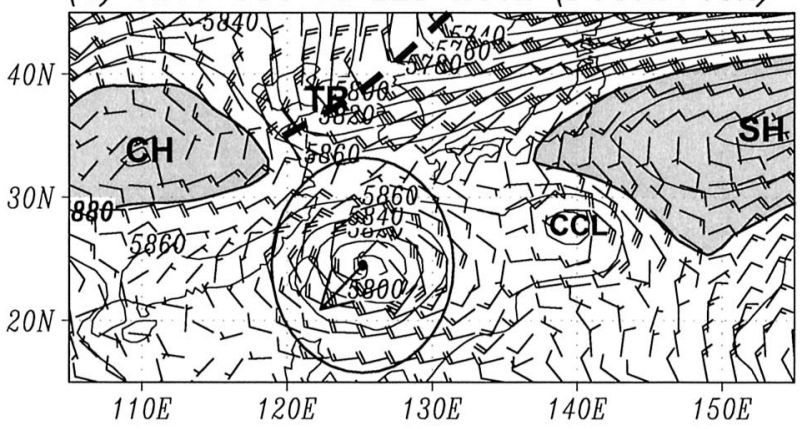

(c) 1200 UTC 05 SEP $2002(F 0400+36 h)$

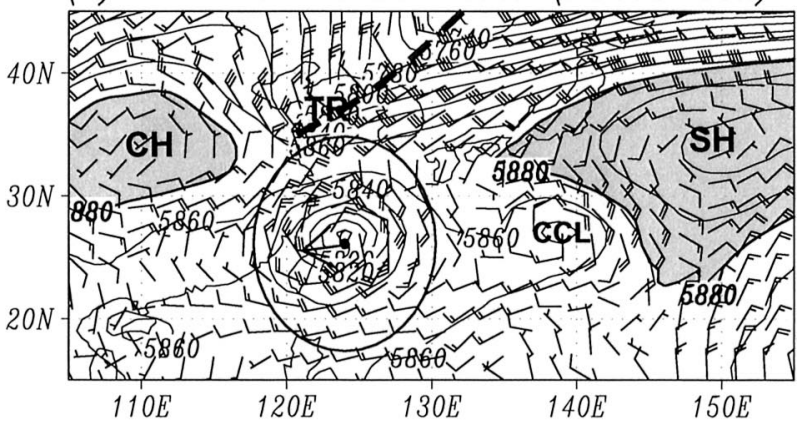

FIG. 8. Geopotential height (contour interval of $20 \mathrm{gpm}$; the area larger than $5880 \mathrm{gpm}$ is shaded) and wind at $500 \mathrm{hPa}$ (one full wind barb $=5 \mathrm{~m} \mathrm{~s}^{-1}$ ) of (a) AVN-A at 1200 UTC 5 Sep 2002, (b) 48-h AVN forecast starting from 1200 UTC 3 Sep 2002 (F0312+48h), and (c) 36-h AVN forecast starting from 0000 UTC 4 Sep 2002 (F0400 $+36 \mathrm{~h})$. The definitions of the bold arrow and the circle are as in Fig. 3.

of the SH and Sinlaku by the presence of the CCL is another factor limiting the influence of the SH on the motion of Sinlaku.

On the contrary, the steering flow $\left[\mathbf{V}_{\mathrm{SDLM}}\left(q_{\mathrm{CH}}^{\prime}\right)\right]$ associated with $q_{\mathrm{CH}}^{\prime}$ (Fig. 6, fourth row from bottom) constantly and robustly advects Sinlaku southwestward at about $7 \sim 8 \mathrm{~m} \mathrm{~s}^{-1}$. The summation of the steering flow associated with $q_{\mathrm{SH}}^{\prime}$ and $q_{\mathrm{CH}}^{\prime}$ provides a west-southwestward motion, which is much larger than the actual motion of Sinlaku. Apparently there must be some missing eastward advection effect from other dynamical systems. Indeed, it is the $q_{\mathrm{TR}}^{\prime}$ that provided a strong eastward 
(a) 1200 UTC 06 SEP $2002(A V N-A)$

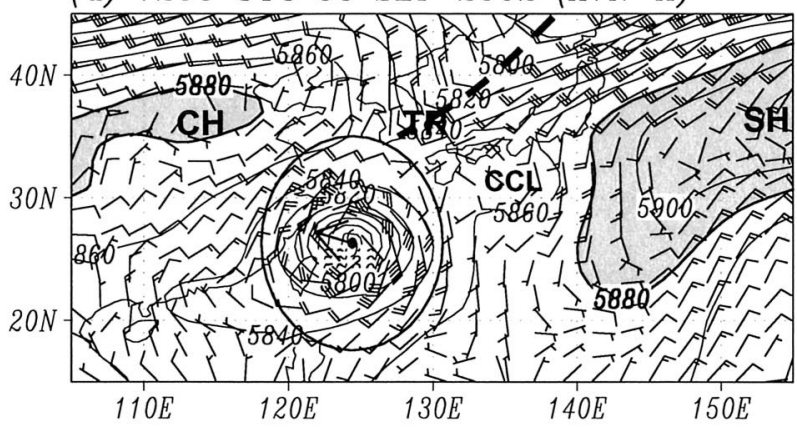

(b) 1200 UTC 06 SEP $2002(F 0312+72 h)$

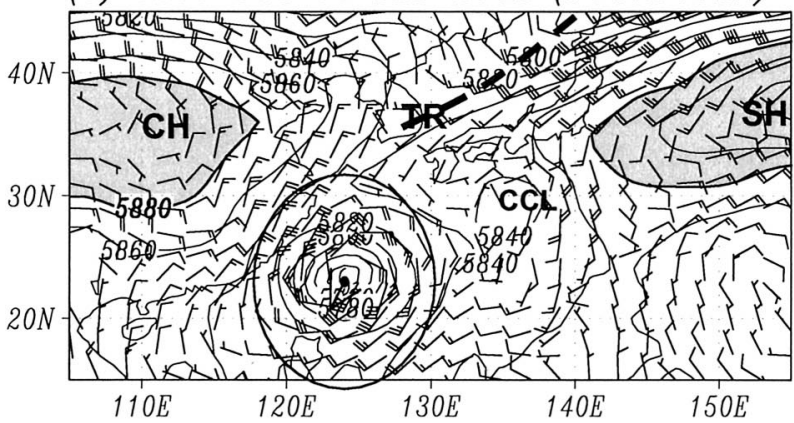

(c) 1200 UTC 06 SEP $2002(F 0400+60 h)$

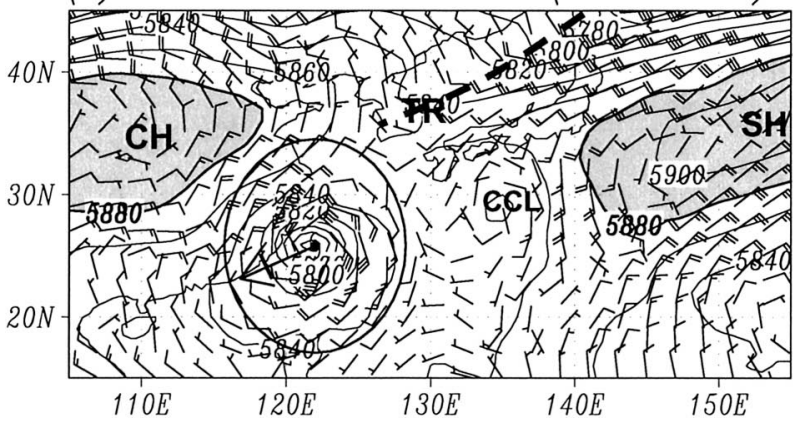

FIG. 9. Geopotential height (contour interval of $20 \mathrm{gpm}$; the area larger than $5880 \mathrm{gpm}$ is shaded) and wind at $500 \mathrm{hPa}$ (one full wind barb $=5 \mathrm{~m} \mathrm{~s}^{-1}$ ) of (a) AVN-A at 1200 UTC 6 Sep 2002, (b) 72-h AVN forecast starting from 1200 UTC 3 Sep 2002 (F0312+72h), and (c) 60-h AVN forecast starting from 0000 UTC 4 Sep 2002 $(\mathrm{F} 0400+60 \mathrm{~h})$. The definitions of the bold arrow and the circle are as in Fig. 3.

steering flow $\left[\mathbf{V}_{\mathrm{SDLM}}\left(q_{\mathrm{TR}}^{\prime}\right)\right]$ (Fig. 6, fifth row from bottom), peaking at $8 \mathrm{~m} \mathrm{~s}^{-1}$ on 0600 UTC 6 September. The result here strongly suggests that the strengthening of the eastward steering due to the deepening TR plays a crucial role in the deceleration of Sinlaku.

Interestingly, the steering flow associated with $q_{\mathrm{SH}}^{\prime}$, $q_{\mathrm{CH}}^{\prime}$, and $q_{\mathrm{TR}}^{\prime}$ (Fig. 6, first row from top) is fairly close to the actual motion of Sinlaku, indicating their dominant role in affecting the movement of Sinlaku, while $q_{\text {CCL }}^{\prime}$ plays a minor role in impeding Sinlaku from moving northward over the early time period. All in all, our analyses show that, during 1200 UTC 4 September to
1200 UTC 5 September, the slowdown of Sinlaku is mainly related to the weakening and retreat of the SH and the approaching deepening midlatitude TR. After 0600 UTC 6 September, as the influence from TR gradually decreases, such an effect on steering flow tends to be offset by the continuous weakening of SH. Therefore, $\mathrm{CH}$ gradually dominates and leads to the acceleration of Sinlaku toward mainland China on 7 September.

\section{2) AVN FORECAST}

The comparison of the best track of Sinlaku and two AVN forecasts, initialized at 1200 UTC 3 September (F0312) and 0000 UTC 4 September (F0400), respectively, is shown in Fig. 1. It can be found that in F0312, the model track moderately deviates to the south from the best track for the first $42 \mathrm{~h}$, then deviates farther southward, and slows down afterward. In short, the entire forecast from F0312 has a significant southward bias. For F0400, the model storm moves too fast during the first $24 \mathrm{~h}$; after that it does capture the slowdown process, but still deviates too far to the south. To investigate why the AVN model fails to predict the slowdown of Sinlaku and falsely predicts the southward dip of the track (as shown in Fig. 1), in this section the above PV diagnosis is again applied to the forecast products of both F0312 and F0400.

Figures 7, 8, and 9 show the comparison of the 500$\mathrm{hPa}$ geopotential height and wind fields among AVNA (Figs. 7a, 8a, and 9a), F0312 (Figs. 7b, 8b, and 9b), and F0400 (Figs. 7c, 8c, and 9c) at three verification times (1200 UTC 4, 5, and 6 September, respectively). In general, the evolution of the TR and CCL in AVNA are well captured by the forecasts of F0312 and F0400. The comparison of Figs. 7a, 7b , and 7c at 1200 UTC 4 September shows that the forecasts from F0312 (Fig. 7b) and F0400 (Fig. 7c) are very much in agreement with the AVN-A (Fig. 7a). However, one day later, at 1200 UTC 5 September, it is apparent that the forecasted $\mathrm{CH}$ is too strong and too broad in both F0312 (Fig. 8b) and F0400 (Fig. 8c) as compared to the AVNA (Fig. 8a). The overdevelopment of the $\mathrm{CH}$ in F0312 and F0400 remains at 1200 UTC 6 September (Figs. $9 \mathrm{~b}, \mathrm{c})$, while the corresponding $\mathrm{SH}$ is weaker in the forecasts (Figs. 9b,c) than that in the analysis (Fig. 9a).

The time series of the model's storm motion vector and the steering flow associated with each different PV perturbation are shown in Fig. 10. The comparison of the motion vector associated with the best track $\left(\mathbf{V}_{\mathrm{BT}}\right)$ and with the forecasted tracks $\left(\mathbf{V}_{\mathrm{BT}-F 0312}\right.$ and $\left.\mathbf{V}_{\mathrm{BT}-F 0400}\right)$ clearly shows the southward bias between 0600 UTC 5 September and 1200 UTC 6 September for F0312, and the slight southward deviation and slower movement after 1800 UTC 6 September. For F0400, the southward deviation appears and increases with time after 0000 UTC 6 September. 


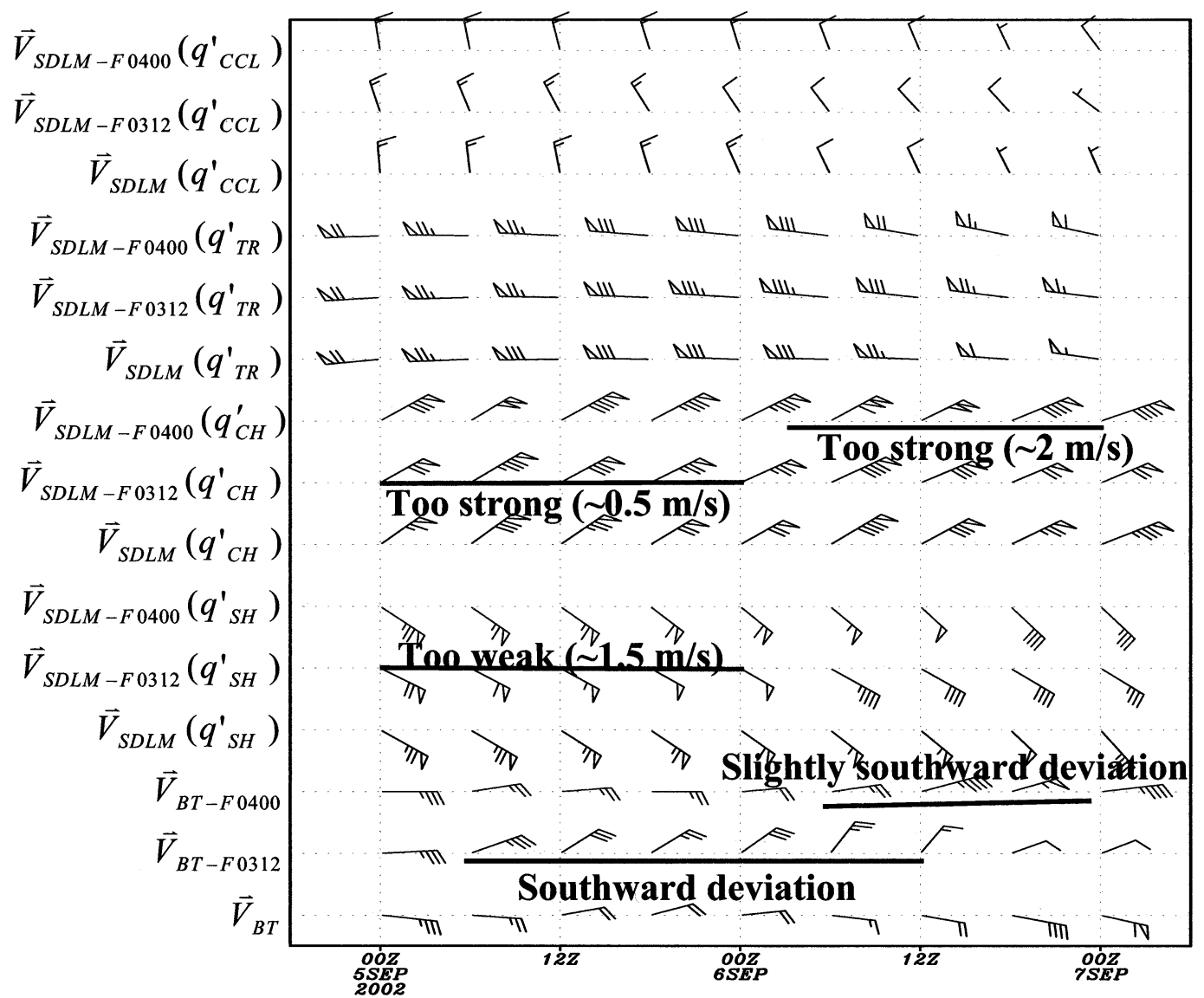

FIG. 10. The time series of the model's storm movement $\left(\mathbf{V}_{\mathrm{BT}}, \mathbf{V}_{\mathrm{BT}-\mathrm{F} 0312}\right.$, and $\left.\mathbf{V}_{\mathrm{BT} \text {-F } 0400}\right)$ and the steering flow (averaged in the inner $3^{\circ}$ latitude between 975 and $300 \mathrm{hPa}$ ) associated with the total PV perturbation, and the PV perturbations of SH, CH, TR, and CCL, individually, for the AVN-A, F0312, and F0400. One full wind barb (a flag) represents 1 (5) $\mathrm{m} \mathrm{s}^{-1}$.

Not surprisingly, because of the accurate forecasts of TR and CCL in both F0312 and F0400 as mentioned above (see Fig. 7), the steering flow associated with TR and CCL (cf. the motion vectors over the top six rows in Fig. 10) for AVN-A, F0312, and F0400 are nearly identical.

Nevertheless, comparing the $\mathrm{SH}$ and $\mathrm{CH}$ fields in F0312 and AVN-A, it is seen in Fig. 10 that the reduced (by about $1.5 \mathrm{~m} \mathrm{~s}^{-1}$ ) southeasterly steering flow associated with the weaker SH and the increased (by about $0.5 \mathrm{~m} \mathrm{~s}^{-1}$ ) northeasterly steering flow associated with stronger $\mathrm{CH}$ together explain why the model track of F0312 has a consistent southward deviation.

The difference in the SH between F0400 and AVNA is less obvious than that between F0312 and AVNA. Therefore only a slight difference in steering flow associated with the $\mathrm{SH}$ is found between F0400 and AVN-A. It appears that the increased (by about $2 \mathrm{~m} \mathrm{~s}^{-1}$ ) northeasterly steering flow associated with stronger $\mathrm{CH}$ in F0400 plays an essential role for the southwestward track bias in the later period.

\section{Summary}

In this study a potential vorticity diagnosis is applied to investigate the factors affecting the decrease of the forward motion of Typhoon Sinlaku and to evaluate why the operational numerical model (i.e., AVN) failed to predict this motion and had a southward bias as Sinlaku approached the offshore northeastern Taiwan. The analysis attributes the initial deceleration mainly to the retreat of the Pacific SH and the influence of the deepening midlatitude TR. The upper-level CCL played a minor role in impeding Sinlaku from moving northward, while the $\mathrm{CH}$ over mainland China exerted a strong westward steering on Sinlaku. Because the steering effect from the above four systems ( $\mathrm{SH}, \mathrm{TR}, \mathrm{CCL}$, and $\mathrm{CH}$ ) tend to cancel one another out, the subtle interaction among them makes it difficult to make a precise track forecast. Further analyses of the AVN forecasts show that the models overestimate the strength of the $\mathrm{CH}$ but underestimate the strength of $\mathrm{SH}$, thus leading to the southward bias with an additional associated northeasterly steering flow. 
Over all, the relative steering effect from the $\mathrm{SH}$, TR, $\mathrm{CCL}$, and $\mathrm{CH}$ on typhoon tracks in this area is not to be taken lightly. The PV diagnosis provides a means to evaluate all these factors affecting the motion of a tropical cyclone. The analysis does identify that the underestimation of the $\mathrm{SH}$ and the overestimation of the $\mathrm{CH}$ are the primary factors leading to the southward bias of the model track in AVN. This result provides a piece of important information on where the foci should be in running numerical sensitivity experiments if one wants to investigate what caused these critical model errors. The above findings also illustrate the benefit of running targeting studies to identify flow features that are important in steering tropical cyclones. For example, Observing System Simulation Experiments (OSSEs) replicating a targeting strategy could be evaluated using the techniques shown here to test the impact of better initializing particular flow pattern on the forecast of the cyclone track.

It is our belief this study will shed light on the quantitative evaluation of the typhoon track analysis and forecast and should benefit the typhoon forecast, as well as the observing (Aberson 2003) and modeling strategies. We are in the process of making such analysis operational at the Central Weather Bureau in Taiwan and expect that it would provide some valuable information for the typhoon researchers and forecasters. Note that in this paper more emphasis is put on the impact of different atmospheric systems on the typhoon motion. Yet the air-sea interaction may also play some important roles on the evolution of typhoons, especially when they move slowly (Lin et al. 2003a,b). This issue may also need to be addressed in the PV diagnosis through the impact of the sea surface potential temperature (Huo et al. 1998).

Acknowledgments. The authors would like to thank Drs. Tien-Chiang Yeh, Hua-Lu Pan, Chin-Tzu Fong, and Wan-Shu Wu for providing the AVN data. We also thank two anonymous reviewers for their helpful remarks. The research is supported by Grants NSC 91-2119-M-002032 and NSC 91-2111-M-002-024.
REFERENCES

Aberson, S. D., 2003: Targeted observations to improve operational tropical cyclone track forecast guidance. Mon. Wea. Rev., 131, $1613-1628$.

Charney, J. G., 1955: The use of primitive equations of motion in numerical prediction. Tellus, 7, 22-26.

Davis, C. A., 1992: Piecewise potential vorticity inversion. J. Atmos. Sci., 49, 1397-1411.

__ , and K. A. Emanuel, 1991: Potential vorticity diagnostics of cyclogenesis. Mon. Wea. Rev., 119, 1925-1953.

Hoskins, B. J., M. E. McIntyre, and A. W. Robertson, 1985: On the use and significance of isentropic potential-vorticity maps. Quart. J. Roy. Meteor. Soc., 111, 877-946.

Huo, Z., D.-L. Zhang, and J. Gyakum, 1998: An application of potential vorticity inversion to improving the numerical prediction of the March 1993 superstorm. Mon. Wea. Rev., 126, 424-436.

Lin, I.-I., W. T. Liu, C.-C. Wu, J. C. H. Chiang, and C.-H. Sui, 2003a: Satellite observations of modulation of surface winds by typhoon-induced ocean cooling. Geophys. Res. Lett., 30, 1131, doi: 10.1029/2002GL015674.

—_ and Coauthors, 2003b: New evidence for enhanced ocean primary production triggered by tropical cyclone. Geophys. Res. Lett., 30, 1718, doi:10.1029/2003GL017141.

Raymond, D. J., 1992: Nonlinear balance and potential vorticity thinking at large Rossby number. Quart. J. Roy. Meteor. Soc., 118, 987-1015.

Shapiro, L. J., 1996: The motion of Hurricane Gloria: A potential vorticity diagnosis. Mon. Wea. Rev., 124, 1497-2508.

_- 1999: Potential vorticity asymmetries and tropical cyclone motion. Mon. Wea. Rev., 127, 124-131.

Wu, C.-C., and K. A. Emanuel, 1995a: Potential vorticity diagnostics of hurricane movement. Part I: A case study of Hurricane Bob (1991). Mon. Wea. Rev., 123, 69-92.

$\ldots$, and _ 1995b: Potential vorticity diagnostics of hurricane movement. Part II: Tropical Storm Ana (1991) and Hurricane Andrew (1992). Mon. Wea. Rev., 123, 93-109.

__ , and Y. Kurihara, 1996: A numerical study of the feedback mechanisms of hurricane-environment interaction on hurricane movement from the potential vorticity perspective. J. Atmos. Sci., 53, 2264-2282.

—_ T.-S. Huang, K.-N. Huang, and T.-C. Yeh, 2000: PV diagnostics of the impact of model initialization on the performance of a typhoon prediction system. Preprints, 24th Conf. on Hurricanes and Tropical Meteorology, Fort Lauderdale, FL, Amer. Meteor. Soc., 423-424.

- — W.-P. Huang, and K.-H. Chou, 2003: A new look at the binary interaction: Potential vorticity diagnosis of the unusual southward movement of Tropical Storm Bopha (2000) and its interaction with Supertyphoon Saomai (2000). Mon. Wea. Rev., 131, 1289-1300. 